\title{
Environmental management options for mitigation of congestion impacts in the Atatürk Urban forest of Bursa, Turkey
}

\author{
S. Gurluk ${ }^{1}$, G. Atanur ${ }^{2} \&$ O. Turan ${ }^{1}$ \\ ${ }^{I}$ Department of Agricultural Economics, Uludag University, Turkey \\ ${ }^{2}$ Department of Landscape Architecture, Uludag University, Turkey
}

\begin{abstract}
The current paper presents the results of a contingent valuation for evaluating the environmental quality in the Atatürk Urban Forest of Bursa, Turkey. The environmental quality parameter under investigation at this recreational site is congestion. Congestion is an important externality having impacts that both limit common facilities and damage natural ecosystems. When users have to pay the same price for lower environmental quality, degraded ecosystems can cause negative impacts on users' satisfaction levels due to congestion. We employed a qualitative response model to learn the covariate effects and mean willingness to pay for shifting congestion levels. Welfare effects of congestion levels offer robust policy options to local policy-makers and on-site management. Consequences point to a resource enlarging policy rather than restrictions on visitor numbers.
\end{abstract}

Keywords: congestion, contingent valuation, payment card, survivor model.

\section{Introduction}

Forest ecosystems, consisting of the physical and biological components of the environment, indicate a stable structure. An important piece of the forest ecosystem, human impacts cause important environmental externalities by interfering in that structural stability. Fundamentals of environmental issues depend on production and consumption incentives. Those incentives creating environmental externalities linked to economic efficiency principle are not considered for resource allocation. The reasons inefficient resource allocation is that environmental goods and services have the tendency to become public 
goods, non-trade goods and infinite goods. Individuals who want to buy private goods consider both characteristics of a private good and its quality levels while making choices. After all, there is no market price for environmental goods and services as mentioned earlier. If natural resources had a market price, environmental pollution and quality levels would be expected to be at lower levels (Nielsen et al. [22]; Bell and Leeworthy [5]). Also, a zero level of environmental pollution and high-quality degradation mean that there is no activity in the natural resources. Therefore the incentives, raising a community's welfare, damaging environmental quality, and partially causing environmental pollution are inevitable although this stance is not supported by some environmental protectionists. However the environmental damages and losses should be kept at optimal levels. In other words, policy makers should consider the carrying capacity of nature while making choices regarding public access (Hanley and Spash [17]; Smith [24]).

An important externality, regarding the carrying capacity of nature and a community's welfare, is congestion. Forest-based recreational sites that comprise the main topic of the current study are affected by the congestion externality. Especially open green areas, city parks, national parks, and similar sites provide recreational opportunities such as picnicking, camping, trekking, hiking, and viewing nature. These activities contribute to individuals in the daily solitude of their lives in terms of moral motivation, regeneration of spiritual and mental wellbeing (Choi [11], Zhu and Zhang [26]). Increasing population, shifting community structure, and a more frenetic lifestyle have increased people's needs to return to nature and ecological leisure activities have in turn increased outdoor recreational demand and consequently caused the congestion externality mentioned above. This rapid growth in demand increases the importance of problem of congestion in forest-based recreational sites due to ecological and social costs. Individual willingness to pay (WTP) for deteriorated environmental quality can be reduced and the site's economic benefits to the community may decrease.

The current study was carried out in a Turkish urban forest, which is designated as the Atatürk Urban Forest of Bursa (AUFB). The AUFB is located in the northwest part of Turkey and was founded in memory of Atatürk who established the Turkish Republic. The City of Bursa used to be known as "Green Bursa" and was an important agricultural settlement because of its productive plains. Today, Bursa is an important industrial city and home to automotive and textile industries. The City of Bursa began taking emigrants at an increasing rate due to the employment possibilities created, and became the fourth biggest city of Turkey in terms of population. As rapid urbanization and population increases bring overcrowding issues to the cities, it creates industrial and urban pressures on the green belt (Atmiş et al. [2]). In this context, efficient management of existing green areas has gained great importance.

AUFB's ecosystem services provide important use and non-use benefits for the region such as recreational use, habitats for native species, regulation of atmospheric quality, and landscape amenities. It has facilitates for activities such as picnicking, cycling, hiking, and observing scenic views. 
The AUFB was turned over to Bursa Nilufer Local Management by the General Directories of National Parks of the Ministry of Forest-Turkey. It has an area of 128 hectares (ha) and this area is dedicated to conservation area (50 ha), fender land (54 ha) and flood control and forestation ( 8 ha) while the remaining part of 16 ha is open to visitor uses. The site management has maintained that an area of only 6.75 ha is open for visitor use, and the remaining area is in parking lots. The General Directorate of National Parks recommends that the maximum visitor rate for the site be $70 \mathrm{~m}^{2}$ per capita. However Nilufer local management has not restricted visitor rates. Within current policy, the forest ecosystem of the site has been degraded due to congestion, and public welfare is negatively affected by this policy. Additionally, The AUFB experiences wildfires every two to three years. Although management issues are being experienced, the AUFB is an appealing recreation site because it is very close to downtown and has fresh air due to high altitude (AUFB, 2008).

Observable prices of social welfare losses and ecological deteriorations due to congestion don't exist in the regular market. It is necessary to employ user's valuation of non-marketed goods such as urban forests and improved environmental quality. A contingent valuation study dependent on the payment card technique is employed and visitors to reveal their WTP over various congestion levels. More information on the survey technique, contributions to current literature and other explanations are available in the materials and methods section of this study.

\section{Materials and methods}

Research material consists of face-to-face surveys administered in the AUFB. The AUFB matches the "urban type recreational site" classification according to Rosenthal and Walsh. Given this classification, land and water recreational sites are separated into five distinct indicators which are labeled as: remoteness of site, location of area, evidence of humans, user density, and existence of managerial activities. The AUFB is an accessible recreation site that is served by various public transportation vehicles and private transportation. It is very close to the city of Bursa, and these features make the site very busy. The industrial city of Bursa is growing and this causes some issues such as congestion in the parks and pressures to green areas in the Bursa. While the previous issue is related to optimal resource use, the latter issue is related to total value of the resources.

In this context, after the priori meetings with site management, a more convenient survey form for studying the visitor profile was constituted. The resource evaluating and congestion-testing survey study, which has following characteristics, was administered to the AUFB visitors in May and June of 2010. The surveys had three sections. Primarily, main aims of survey and natural resource values were explained and described to the respondents. In the first section of the questionnaire, user's recreational behaviors were investigated. Respondent's starting points to the site, past visits, duration of travel time to the site, and familiarity with outdoor activities offered at the site was investigated. In 
section two, respondents were interviewed in terms of users' utilization of the resources available. Environmental quality concerns show different congestion types in the AUFB. So a brief informational statement about congestion types was introduced to respondents in third section. It was assumed that each respondent experiences and assesses five different congestion types in the AUFB. The information regarding congestion levels presented to respondents is given in Appendix section of this paper. After this brief explanation, respondents were asked a WTP question about a randomly selected congestion type. For this purpose, a payment card was shown and respondents were asked to mark how much they would be willing to pay for selected congestion type. The last section consisted of demographic inquiries while keeping respondents anonymous. The respondents' attitudes on environmental protection, sustainable development, and efficient resource use were investigated in the last section. Thus, total of 200 respondents completed the survey via the face to face survey method. The frequency distribution relating to demographic structure of the respondents in the survey is given in Table 1.

Table 1: Frequency distribution of respondents' demographic structure in the survey.

\begin{tabular}{ccc}
\hline Variable & Description & Distribution (\%) \\
\hline \multirow{2}{*}{ Gender } & Male & 87.5 \\
& Female & 12.5 \\
\hline \multirow{3}{*}{ Age groups } & $19-25$ & 4.5 \\
& $26-30$ & 9.0 \\
& $31-40$ & 41.5 \\
& $41-60$ & 41.0 \\
& $60-85$ & 4.0 \\
\hline \multirow{3}{*}{ Annual household income } & $<9600$ & 23.0 \\
& $9600-12800$ & 25.0 \\
& $12801-20000$ & 31.5 \\
& $>20000$ & 20.5 \\
\hline \multirow{2}{*}{ Education level } & Primary school & 16.5 \\
& High school & 49.5 \\
& University degree & 34.0 \\
\hline
\end{tabular}

Until recently, several papers examined non-market valuation on congestion impacts although the papers examining the congestion at the recreational sites are limited. Anderson and Bonsor (1974), Cicchetti and Smith [12] were among the first authors who tried to measure congestion through willingness to pay. Cesario [10] emphasized the importance of congestion by stating that any individual visiting a site would be willing to pay some positive amount of money for the right to visit the site when they are fewer visitors. McConnell [21] 
demonstrated how the WTP function can be used to determine the optimal capacity of beaches while Walsh et al. [25] investigates the effects of congestion at ski areas to evaluate policy options. Jakus and Shaw [20] stressed that the congestion valuation is not only important from the ecological viewpoint but also from the human perspective.

The current study assumes that visitors' trip decisions are based on past experiences, advance expectations, and environmental attitudes. Therefore we take into account the WTP directly by evaluating ex ante and ex post measures of congestion. Furthermore we examine the effects of visitors' socio-economic structure and environmental attitudes on congestion valuation and urban forest management. In this context dependent variable WTP is the value that total number of past and future visits is multiplied by pointed WTP amount on the payment card presented. After measuring the covariates impacts on congestion, we employed the survivor function to calculate mean WTP without covariates. Correlation of different congestion types from the respondents arises when a single model is estimated for all congestion types. A random effect linear regression model is as follows:

$\mathrm{i}=1,2, \ldots, \mathrm{n}$

$$
Y_{i j}=\alpha+\beta S_{i j}+\psi_{1} D_{2}+\psi_{2} D_{3}+\psi_{3} D_{4}+\psi_{4} D_{5}+\lambda E_{i j}+\eta_{i}+\varepsilon_{i}
$$

$\mathrm{j}=1,2,3,4,5$

where the $Y_{i j}$ is dollar value of the WTP for individual i, $S_{i j}$ is explanatory variables such as demographic variables and attitudes for individual i, $D$ represents the dummy variables for congestion levels on a 1-5 scale, $E$ is respondents' attitudes on environmental protection and $\alpha, \beta, \psi, \lambda$ are unknown parameters to be estimated. The coefficients $\psi_{1}, \psi_{2}, \psi_{3}, \psi_{4}$ indicate, respectively, how much larger (or lower) the response functions for congestion models $\mathrm{C}_{2}, \mathrm{C}_{3}$, $\mathrm{C}_{4}$ and $\mathrm{C}_{5}$ are than the one for congestion model $\mathrm{C}_{1}$. Thus the $\psi_{1}, \psi_{2}, \psi_{3}, \psi_{4}$ measure the differential effects of the qualitative variable classes $\eta_{i}$ is the random coefficient that accounts for the correlations among the evaluations for respondent $I$ and is assumed to be normally distributed with mean 0 and variance $\sigma^{2}$ across all respondents. $\varepsilon_{\mathrm{ij}}$ is the random error term with mean 0 and variance $\sigma^{2}$. Qualitative and quantitative variables used in the statistical analysis are described in Table 2 while their summary statistics are given in Table 3.

\section{Results and discussion}

Qualitative variable regression analysis was undertaken by using SPSS software to identify the factors associated with responses to the payment card WTP question. The parameter estimates of the qualitative variable regression analysis for WTP of the AUFB are shown in Table 4. The coefficients for the explanatory variables are also the marginal effects for those variables. They might be tested via t-values individually. Instead, we employed $F$-test to understand if the regression equation as a whole is significant. The $F$-test is a joint test of the 
Table 2: $\quad$ Descriptions of variables.

\begin{tabular}{|c|c|}
\hline Variables & Explanations \\
\hline WTP & $\begin{array}{c}\text { Dollar value of WTP for randomly selected congestion } \\
\text { level }\end{array}$ \\
\hline $\mathrm{D} 2, \mathrm{D} 3, \mathrm{D} 4, \mathrm{D} 5$ & $\begin{array}{l}\text { Dummy variables representing congestion levels C2, } \\
\qquad \mathrm{C} 3, \mathrm{C} 4 \text { and } \mathrm{C} 5\end{array}$ \\
\hline Gender & 1: Male, $0:$ Female \\
\hline Age & Age of respondents \\
\hline Income & $\begin{array}{l}\text { 1: If respondents' household income is more than } \\
\text { 20,000USD annually 0: Otherwise }\end{array}$ \\
\hline Sus_Dev_Sens & $\begin{array}{l}\text { Sustainable development sensitivity of respondent 1: } \\
\text { Strong, 2:Neutral, 3: Weak acceptance }\end{array}$ \\
\hline Sens_to_biodiversity & $\begin{array}{c}\text { Respondent's sensitivity to biodiversity, 1: Strong } \\
\text { acceptance, 2:Acceptance, 3: Neutral, 4: Not } \\
\text { acceptable, 5: Weak acceptance }\end{array}$ \\
\hline Effic_res_use & $\begin{array}{l}\text { Respondent's attitude to efficient resource use 1: } \\
\text { Strong acceptance, 2:Acceptance, 3: Neutral, 4: Not } \\
\text { acceptable, 5: Weak acceptance }\end{array}$ \\
\hline
\end{tabular}

Table 3: $\quad$ Summary statistics of covariates.

\begin{tabular}{|c|c|c|c|c|}
\hline Variables & Mean & Std.Dev. & Min. & Max. \\
\hline Gender & 0.88 & 0.332 & 0 & 1 \\
\hline Age & 40.72 & 9.893 & 19 & 81 \\
\hline Income & 0.20 & 0.401 & 0 & 1 \\
\hline Sus_Dev_Sens & 1.62 & 0.597 & 1 & 3 \\
\hline Sens_to_biodiversity & 2.38 & 0.944 & 1 & 5 \\
\hline Effic_res_use & 2.44 & 1.124 & 1 & 5 \\
\hline
\end{tabular}

hypotheses that all the coefficients except the constant term are zero (Greene [13]). If all the slopes are zero, the multiple correlation coefficients are zero as well.

Thus, the F-test is based on the value of $R^{2}$ as following

$$
F[k-1, n-k]=\frac{R^{2} /(k-1)}{\left(1-R^{2}\right) /(n-k)}
$$

when $k$ and $n$ are the numbers of variables and sample size, respectively. The $R^{2}$ value was 0.219 and thus the value of $F_{1}[9,190]$ was 5.91 . We can infer from the 
F-test results for significance of the qualitative regressions. Given to the F-test result, which is larger than the 95 percent critical values of 1.88 , we conclude that the data are inconsistent with the hypothesis that all the slopes in the models are zero.

Table 4: $\quad$ Parameter estimates for the qualitative response model.

\begin{tabular}{|c|c|c|c|c|}
\hline Parameter & Variables & Estimates & Std. Error & t-value \\
\hline Intercept & $\alpha$ & 37,053 & 21,251 & 1,744 \\
\hline D_2 & $\psi_{1}$ & 11,412 & 9,590 & 1,190 \\
\hline D_3 & $\psi_{2}$ & $-9,568$ & 9,723 & $-0,984$ \\
\hline D_4 & $\psi_{3}$ & $-30,689$ & 9,652 & $-3,180$ \\
\hline D_5 & $\psi_{4}$ & $-41,213$ & 9,897 & $-4,164$ \\
\hline Gender & $\beta_{1}$ & 10,378 & 9,883 & 1,050 \\
\hline Age & $\beta_{2}$ & $-0,082$ & 0,315 & $-0,262$ \\
\hline h_income & $\beta_{3}$ & 1,004 & 7,983 & 0,126 \\
\hline Sus_dev_sens & $\lambda_{1}$ & $-11,926$ & 5,368 & $-2,222$ \\
\hline Sens_to_biod & $\lambda_{2}$ & 3,920 & 3,362 & 1,166 \\
\hline Effic_res_use & $\lambda_{3}$ & 7,450 & 2,827 & 2,635 \\
\hline$R^{2}$ & 0,219 & & & \\
\hline
\end{tabular}

\subsection{The impacts of covariates of demographic structure}

In the model, the gender variable has positive sign. This suggests that males are more inclined to increasing the WTP amount than females. If the coefficients of variables, except dummy variables and gender, are multiplied by their mean values, we can measure congestion impacts over gender. Table 5 indicates the mean WTP values according to gender and shifting congestion levels.

Table 5: $\quad$ Impacts of gender for shifting congestion levels.

\begin{tabular}{|c|c|c|c|c|}
\hline Congestion levels & $\begin{array}{c}\text { Male } \\
\text { mean WTP }\end{array}$ & & $\begin{array}{c}\text { Female } \\
\text { mean WTP }\end{array}$ & \\
\hline I & 34.98 & \multirow{5}{*}{$-78,5 \%$} & 28.06 & \multirow{5}{*}{$-97,8 \%$} \\
\hline II & 42.60 & & 35.67 & \\
\hline III & 28.60 & & 21.68 & \\
\hline IV & 14.52 & & 7.60 & \\
\hline $\mathrm{V}$ & 7.50 & & 0.60 & \\
\hline
\end{tabular}


Given the information in Table 5, there is a difference of 19.3 percent between the mean WTP of the congestion levels I and V, and females suffer more from congestion compared to males.

Rather, we can infer from the table that solitude is more valuable to females. The age variable has negative sign. The mean WTPs for shifting congestion levels are calculated, in Table 6, by considering mid-points of any class representing age groups.

Table 6: $\quad$ Impacts of age groups for shifting congestion levels.

\begin{tabular}{cccccc}
\hline & \multicolumn{5}{c}{ Congestion Levels } \\
\cline { 2 - 6 } Age Groups & $\mathrm{C}_{1}$ & $\mathrm{C}_{2}$ & $\mathrm{C}_{3}$ & $\mathrm{C}_{4}$ & $\mathrm{C}_{5}$ \\
\hline $19-25$ & $36.00^{*}$ & 43.61 & 29.63 & 15.55 & 8.53 \\
$26-30$ & 35.68 & 43.29 & 29.30 & 15.23 & 8.20 \\
$31-40$ & 34.84 & 42.88 & 28.89 & 14.81 & 7.79 \\
$41-60$ & 34.44 & 42.06 & 28.07 & 13.99 & 6.97 \\
$60-85$ & 33.24 & 40.85 & 26.87 & 12.79 & 5.77 \\
\hline
\end{tabular}

* Means willingness to pay.

Generally one may said that the respondents prefer the congestion level-II with a higher WTP amount compared to other levels. This is because covariate impacts are interpreted as showing that security worries dominate congestion level-I preferences. Boxall et al. [7] states that, by supporting this consequence, in the initial range of congestion it is possible that a visitor will be indifferent or even value an additional encounter.

Income has a positive impact over the WTP. If we consider that those who have 20000 USD/year salaries are in a high income level, we may maintain the existence of income effects among lower income groups. Only twenty percent of respondents have over $20000 \mathrm{USD} /$ year salaries. In this context, we can state that the visitors of the AUBF are from the medium or lower income groups. Heinen [19], Gürlük and Rehber [14] observed similar consequences in their studies of people's attitudes for the wildlife in National Parks in Nepal and Turkey, respectively. The positive attitudes were measured for protection of the parks, and found to be highly correlated with demographic factors of visitors.

\subsection{The impacts of covariates of environmental attitudes}

The respondents were investigated in three parameters in terms of environmental behaviors and attitudes. Those parameters are: general sensitivity to environment and sustainability, sensitivity to biodiversity of the site, and optimal resource use. The respondents' sensitivity to sustainable development was linked to controlled industrial growth. This implies that the respondents are more tend to WTP as long as the sensitivity of sustainable development. In other words, a respondent who has a strong attitude about sustainable development tends to 
make higher payments due to shifting congestion levels than other respondents. Sensitivity to biodiversity parameter has a positive sign. Consequently it implies that the respondents' WTP increases even if they are non-sensitive to biodiversity. Likewise, sensitivity to optimal resource use has a positive impact over the WTP amounts at the decreasing sensitivity. As a consequence we may infer that the respondents tend to lower WTP for the last two investigations due to prejudices about restricted recreational activities, although they are sensitive to general environmental protection. Thus, a policy regarding recreational site's expansion, rather than the policy of restricted visitor rates, may be preferred in order to raise visitor satisfaction. Therefore it is likely that the visitors' welfare level increases with the resource expansion policy. Table 8 supports that view. The impacts of optimal resource use parameter was examined in a three scales, strong, medium, and weak, and linked to higher and lower income groups. Results indicate that the impacts of income groups, in terms of efficient resource use, don't create an important difference in assessing the congestion levels. Consequences point out, again, the resource enlarging policy rather than restrictions.

\section{Conclusions}

In this paper we have examined environmental quality measurement in a highdensity urban forest, Atatürk Urban Forest of Bursa (AUFB), by considering the congestion parameter. Congestion is an important externality regarding the carrying capacity of nature and a community's welfare. When the congestion externality exists in a recreational site, the quality of the recreational activities experienced by users deteriorates. Such externalities can limit common facilitates and damage natural ecosystems. Consequently, users pay the same price for lesser environmental quality, and it causes diminishing human welfare. Although there are many policy options to resolve issues in the AUFB, the options of resource expansion and visitor restriction come forward in order to mitigate congestion effects in this high density urban forest.

Qualitative response models have considerable features on measuring the respondents' environmental attitudes and socio-economic characteristics to shifting congestion levels. Findings show that the willingness to pay for decreasing congestion externality indicates increases up to 98 percent depending on age groups and gender. The respondent's environmental behaviors and attitudes provide important insights to policy makers. Those parameters were examined under three sections, which are the sensitivity to general environmental protection, biodiversity, and optimal resource use. Consequences emphasize that resource expansion policy was preferred, rather than a visitorrestriction policy, by the AUFB's visitors. In other words, visitor's welfare levels increase with the application of the resource expansion policy.

Local park management does not take the congestion into consideration regarding onsite management. Respondents prefer the congestion level-II with a higher WTP amount (Table 7). The mean WTP for congestion level-II was 42.5 USD per visit while it was 7.5 USD for the congestion level-V. It accounts for 
about 1,000,000 USD welfare losses annually due to current policy. Congestion in a forest-based recreational site makes the quality of the recreational activities worse than uncongested condition. The estimated reduced welfare values have supported this phenomenon in the AUFB.

Table 7: Impacts of visitors' attitudes for efficient resource use to shifting congestion levels.

\begin{tabular}{|c|c|c|c|c|c|c|}
\hline \multicolumn{3}{|c|}{ Congestion Levels } \\
\hline \multirow{2}{*}{$\begin{array}{c}\text { Income } \\
\text { levels }\end{array}$} & $\begin{array}{c}\text { Efficient } \\
\text { Resource } \\
\text { use }\end{array}$ & $\mathrm{C}_{1}$ & $\mathrm{C}_{2}$ & $\mathrm{C}_{3}$ & $\mathrm{C}_{4}$ & $\mathrm{C}_{5}$ \\
\hline \multirow{2}{*}{$\begin{array}{c}\text { Higher } \\
\text { income }\end{array}$} & Strong & 28,37 & 35,97 & 21,99 & 7,91 & 0,89 \\
\cline { 3 - 8 } & Medium & 38,30 & 45,91 & 31,92 & 17,84 & 10,83 \\
\cline { 3 - 8 } & Weak & 48,23 & 55,84 & 41,85 & 27,77 & 20,76 \\
\hline \multirow{2}{*}{$\begin{array}{c}\text { Lower } \\
\text { income }\end{array}$} & Strong & 27,70 & 35,31 & 21,32 & 7,24 & 0,23 \\
\cline { 3 - 8 } & Medium & 37,63 & 45,24 & 31,25 & 17,17 & 10,15 \\
\cline { 3 - 8 } & Weak & 47,57 & 55,17 & 41,19 & 27,11 & 29,57 \\
\hline
\end{tabular}

\section{Appendix}

\section{Congestion levels}

Level I: In this level of congestion, there are few individuals around and also noise does not occur.

Level II: In this level of congestion, there are a couple of groups of visitors around and the noise level is low.

Level III: In this level of congestion, there are some visible individuals around, common user facilitates can be busy occasionally and the noise level I is higher than level II.

Level IV: In this level of congestion, you can observe many visitors around and a high noise level surrounds the site. The common user facilitates are busy and many hikers make the trail busy.

Level V: In this level of congestion, recreational site is crowded so that you cannot walk without having to stop. The noise level higher than ever before and making conversations within a group can often be impossible.

\section{References}

[1] Anderson, F.J., Bonsor, N.C., 2001. Allocation, Congestion, and the Valuation of Recreational Resources. Land Economics. 50, 51-57. 
[2] Atmiş, E., Öden, S., Wietze, L., 2007. Urbanization pressures on the natural forests in Turkey: An overview. Urban Forestry and Urban Greening. 6, 8392.

[3] AUFB, 2008. Atatürk Urban Forest of Bursa Working Report, The Municipality of Bursa-Turkey.

[4] Bateman, I.J., Carson, R.T., Day, B., Hanemann, M., Hanley, N., Hett, T., Jones, M., Loomes, G., Mourato, S., Özdemiroğlu, E., Pearce, D., Sugden, R., Swanson, J., 2002. Economic Valuation with Stated Preference Techniques. Edward Elgar Publishing Limited, Cheltenham, UK.

[5] Bell, F.W., Leeworthy, V.R., 1990. Recreational demand by tourists for saltwater beach days. Journal of Environmental Economics and Management. 18, 189-205.

[6] Bowker, J. M., Stoll, J. R., 1988. Use of dichotomous choice non-market methods to value the whooping crane resource. American Journal of Agricultural Economics. May, 372-381.

[7] Boxall, P., Rollins, K., Englin, J., 2003. Heterogeneous preferences for congestion during a wilderness experience. Resource and Energy Economics. 25, 177-195.

[8] Boyle, K. J., Welsh, M. P., Bishop, R. C., 1988.Validation of empirical measures of welfare change: Comment. Land Economics. 64, 94-98.

[9] Brent, R., 1998. Cost-Benefit Analysis for Developing Countries. Edward Elgar Publishing Limited, Cheltenham, UK.

[10] Cesario, F.J., 1980. Congestion and the Valuation of Recreation Benefits. Land Economics. 56, 329-338.

[11] Choi, K., 1998. Measuring congestion effects in a high-density recreational site. The unpublished PhD thesis, Department of Forestry of Iowa State University, Ames, USA.

[12] Cicchetti, C. J., Smith, V. K., 1976. The costs of congestion: An econometric analysis of wilderness recreation. Ballinger, Cambridge, MA, USA.

[13] Greene, W. H., 2003. Econometric Analysis. Prentice Hall, USA.

[14] Gürlük, S. and Rehber, E., 2008. A travel cost study to estimate recreational value for a bird refuge at Lake Manyas, Turkey. Journal of Environmental Management. Vol. 88, 1350-1360.

[15] Haab, T.C., McConnell, E.K., 2002. Valuing Environmental and Natural Resources: the Econometrics of Non-market Valuation. Edward Elgar, Cheltenham, UK, Northampton, USA.

[16] Hanemann, W. M., 1989. Welfare evaluations in contingent valuation experiments with discreet response data: Reply. American Journal of Agricultural Economics. 71, 1057-1061.

[17] Hanley, N., Spash, C.L., 1993. Cost-Benefit analysis and the environment. Edward Elgar Publishing, Cheltenham, UK, Northampton, USA.

[18] Harrison, G.W., Kristrom, B., 1995. On the interpretation of responses in contingent valuation surveys. In: Johansson, P., Kriström, B., Maler, K.G. (Eds.), Current Issues in Environmental Economics. Manchester University Press, UK. 
[19] Heinen, J. T., 1993. Park-people relation in Kosi Tappu wildlife reserve, Nepal: a socio economic analysis. Environmental Conservation. 20, 25-34.

[20] Jakus, P. Shaw, W.D., 1997. Congestion at Recreation Areas: Empirical Evidence on Perceptions, Mitigating Behaviour and management Preferences. Journal of Environmental Management. 50: 389-401.

[21] McConnell, K.E., 1977. Congestion and Willingness to Pay: a Study of Beach Use. Land Economics. 53, 185-195.

[22] Nielsen, A. B., Olsen, S. B., Lundhede, T., 2007. An economic valuation of the recreational benefits associated with nature-based forest management practices. Landscape and Urban Planning. 80, 63-71.

[23] Rosenthal, D. H., Walsh, R. G., 1986. Hiking values and the recreation opportunity spectrum Forest Science. 32, 405-415.

[24] Smith, R.J., 1971. The evaluation of recreation benefits: the Clawson Method in practice. Urban Studies. 8, 89-102.

[25] Walsh, R.G, Miller, N.P., Gilliam, L.O., 1983. Congestion and Willingness to Pay for Expansion of Skiing Capacity. Land Economics. 59, 195-210

[26] Zhu, P., Zhang, Y., 2008. Demand for urban forests in United States cities. Landscape and Urban Planning. 84, 293-300. 